\title{
Exertional dyspnea as initial manifestation of Takayasu's arteritis - A case report and literature review Beatrice Neidhart ${ }^{1}$, Robert Kosek ${ }^{1}$, Lucas M Bachmann ${ }^{2}$ and Claudia Stey*1
}

Address: ${ }^{1}$ Department of Internal Medicine, Medical Policlinic, University Hospital Zurich, Switzerland and ${ }^{2}$ Horten Centre, University of Zurich, Switzerland

E-mail: Beatrice Neidhart - beatrice.wydler@dim.usz.ch; Robert Kosek - robert.kosek@ hin.ch; Lucas M Bachmann - lucas.bachmann@vimed.ch; Claudia Stey* - claudia.stey@dim.usz.ch

${ }^{*}$ Corresponding author

Published: 18 December 200।

BMC Pulmonary Medicine 200I, 1:3

This article is available from: http://www.biomedcentral.com/I47I-2466/I/3

(c) 200I Neidhart et al; licensee BioMed Central Ltd. Verbatim copying and redistribution of this article are permitted in any medium for any noncommercial purpose, provided this notice is preserved along with the article's original URL. For commercial use, contact info@biomedcentral.com
Received: 18 October 2001

Accepted: 18 December 2001

\begin{abstract}
Background: Takayasu's arteritis is a chronic systemic inflammatory disease that usually affects the aorta, its primary branches and occasionally the pulmonary and coronary arteries. Female gender in reproductive age and Asian origin are known factors associated with higher disease prevalence. The clinical manifestations vary considerably and are typically caused by limb or organ ischemia illness and fever. The estimated incidence rate in the western world is 2.6 cases per million persons per year. Occasionally, exertional dyspnea can be the sole primary clinical manifestation of Takayasu's arteritis.

Case presentation: We report the case of a 57-year-old woman who was referred to our institution with increasing exertional dyspnea caused by pulmonary artery involvement in Takayasu's arteritis. In a review of the literature we discuss demographic data, clinical and radiographic findings and available therapeutic options.

Conclusions: Dyspnea due to pulmonary artery involvement can be the initial symptom of Takayasu's arteritis. Simple clinical tests, including a complete pulse-status and blood pressure measuring at both arms can lead to the right diagnosis and should always be done beyond the auscultation of the heart and lungs in patients with dyspnea.
\end{abstract}

\section{Background}

Diagnosis of Takayasu's arteritis is always challenging as the clinical presentation may vary considerably. Especially pulmonary artery involvement is difficult to differentiate from chronic thromboembolic disease since progressive dyspnea on exercise; chest pain and hemoptoe are the most frequent symptoms [3]. A Takayasu arteritis may also mimic idiopathic inflammatory diseases such as Behçet's syndrome, giant cell arteritis and sarcoidosis or infections (e.g. tuberculosis, syphilis). Since inherited vascular diseases and fibromuscular dysplasia may present similarly, they also have to be considered [4].

In 1990, the American College of Rheumatology suggested a set of criteria for the diagnosis of Takayasu's arteritis. The criteria consist of (a) age $<40$ years, (b) claudication of an extremity, (c) decreased brachial artery pulse, (d) > $10 \mathrm{mmHg}$ difference in systolic pressure between the left and right arm, (e) a bruit over subclavian arteries or aorta and (f) angiographic evidence of narrowing or occlusion of the aorta or its primary or proximal branches [5]. Pres- 
ence of three of the six criteria is required for the diagnosis. Our patient fulfilled four of those six.

The median age of patients with pulmonary manifestation in the reviewed articles $[3,10-28]$ was 35 years; eight of 32 patients screened were older than 40 years. This contrasts with the reported median age (25-30 years) at onset of Takayasu's arteritis $[1,4]$. It appears, that the average age at disease onset is higher in patients with pulmonary manifestation as initial localization. We therefore suggest, that the diagnostic criteria for Takayasu's arteritis of the American College of Rheumatology should be adapted accordingly. The age criterion could be abandoned but coronary or pulmonary artery involvement should be considered.

The most common clinical manifestation of Takayasu's arteritis is the affection of the aorta and its main branches [1]. But the involvement of the pulmonary arteries is also well known. Recent articles described pulmonary artery involvement in $14 \%$ to $86 \%$ of all cases with Takayasu's arteritis [6-9]. However, there are only a few cases published, where a Takayasu's arteritis initially presented with pulmonary symptoms as seen in our patient.

In a literature review $[3,10-28,34]$ of the last 10 years we found 33 cases of Takayasu's arteritis in which symptoms relating to pulmonary artery involvement occurred as the initial clinical manifestation. An exclusive involvement of the pulmonary artery with normal aortic angiography, computer tomography or magnetic resonance imaging was described in 11 of 33 cases; in one case confirmed by histological examination. Summarizing the published literature, isolated pulmonary arteries involvement occurs in about a third of all patients. This figure may be an overestimate since none of the cases documented a follow up. Therefore a later affection of the aorta could not be excluded.

In our case we identified the involvement of both pulmonary arteries. There was also MRI evidence of systemic arterial involvement. The distribution of pulmonary affection in the reviewed cases was unequal. In seventeen of the thirty-three cases an affection of the right pulmonary artery was described, in eleven cases both pulmonary arteries were affected, whereas left pulmonary artery involvement was reported once. The predominant role of the right pulmonary artery was described also elsewhere [6-9].

In Takayasu's arteritis systemic-pulmonary shunts are well known. In the reviewed cases we found five coronary-pulmonary, seven broncho-pulmonary and two other systemic-pulmonary shunts. Such artery shunts appear to be indicative of extensive pulmonary artery involvement [9]. Even though Takayasu's arteritis is more common in
Asian countries, the pulmonary artery involvement has not shown any racial or geographic predilection [6]. In the reviewed cases the female to male ratio was 6.5. Although women of reproductive age may typically be affected (female to male ratio 8.5), recent reports confirm an increased frequency in males [4]. The histology commonly describes three lesions: (a) the classic large-vessel granulomatous giant cell arteritis which is similar to the histopathological findings in the aorta and its branches, (b) a vessel-in-vessel disease, which appears to be an organized thrombus with newly formed endovascular arterioles, these vessels may be formed from the vasa vasorum and are branches of the bronchial artery, and (c) a dilation of small blood vessels. It is unclear whether the dilation is a plexogenic arteriopathy of high-grade pulmonary hypertension or if this represents a Takayasu's arteritis of the small arteries $[3,17]$.

Morbidity results from arterial stenosis and aneurysms, which may lead to aortic regurgitation and myocardial infarction, retinopathy or mesenteric vascular insufficiency as well as claudication, renovascular hypertension stroke, and increased pulmonary pressure with dyspnea on exertion. Our patient reported breathlessness already at light activity. In actual practice, the major functional classifications of patients with dyspnea are based on the degree of exertion. However, in assessing the severity of dyspnea variables like the patient's general physical condition and interindividual variation in perception have to be considered. Some useful tests in diagnosing and quantification of dyspnea are timed distance tests (i.e. 6- or 12-minute walk) or cardiopulmonary exercise tests. Reported predictors for morbidity and mortality are hypertension, cardiac involvement aneurysms and retinopathy. Mortality is low with five-year and ten-year survival rates between $70 \%$ and $100 \%$. Major causes of death are congestive heart failure and cerebrovascular complications $[1,2,33]$.

Major complications that lead to an increased morbidity are haemoptysis, severe congestive heart failure, pleural effusion, cavitations with chronic inflammation and pulmonary thrombembolism. Three of 33 patients died, two due to massive haemoptysis and one as a result of postoperative complication after aortic aneurysm resection.

First line Therapy of Takayasu's arteritis is an immunosuppressive treatment primarily with corticosteroids. With glucocorticoid treatment remissions occur in $40-60 \%$ of all patients. About $40 \%$ of all steroid-resistant patients respond to the addition of cytotoxic agents. Approximately $20 \%$ of all patients are resistant to any kind of therapy $[1,2,31]$. Methotrexate appears to be a viable alternative immunosuppressive agent whereas cyclophosphamide treatment should be carefully considered because of substantial risk of toxicity. Hoffmann et al. showed that 
methotrexate apparently induced or facilitated remissions in 13 of 16 patients in whom treatment with glucocorticoids, and in some cases cytotoxic agents, had previously failed [32].

Response to treatment may not be easily determined during follow up. Clinical findings alone are no good disease parameters and the ability to objectively measure disease activity is limited. There is no known serological test, CRP and ESR may be used to differentiate between active and inactive disease status [29]. MRI and CT can visualize the increased vascularisation in the thickened aortic wall. This may indicate active stage of Takayasu's arteritis. In this situation MRI or CT can be used as an auxiliary marker for disease activity [30]. Under therapy a decreased activity was demonstrated by MR-angiography in our case, showing reduction of the gadolinium uptake and in addition lung perfusion scan confirmed an increase in the perfusion of the left lung.

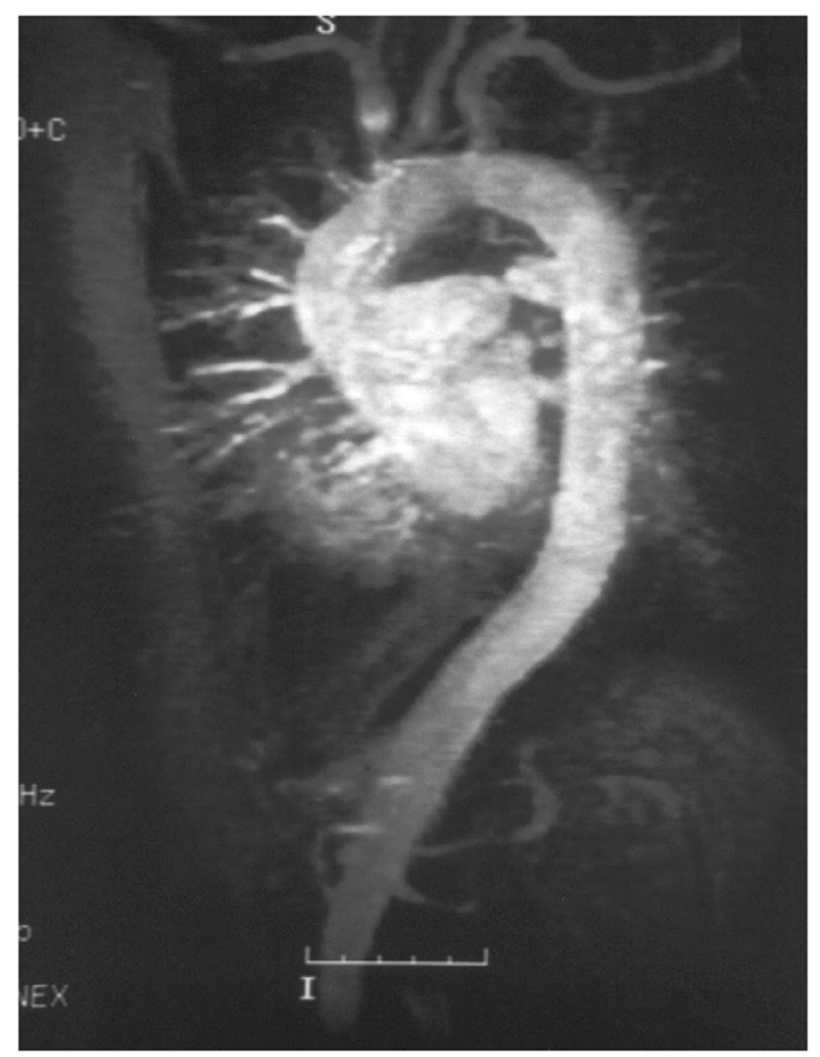

\section{Figure I}

MR-angiography of the chest and neck showing concentric stenosis of the brachiocephalic trunk, the left common carotid artery and the proximal pulmonary arteries predominantly on the left side.

\section{Case presentation}

A 57-year-old housewife was admitted to our department because of dyspnea. A slight dyspnea on exertion started years ago and deteriorated within the last few months leading to shortness of breath at low physical activity. The only associated symptom was an inconstant dry cough. There was no history of former heart or pulmonary problems and the patient didn't take any medication. Indicative for diagnosis was the clinical finding of decreased right radialis pulse and a substantial difference in systolic blood pressure between the left and right arm (130/100 $\mathrm{mm} \mathrm{Hg}$ in the right arm and 160/90 mmHg in the left arm). The pulse rate was 80 beats per minute. The clinical examination further revealed systolic vascular bruits over the $2^{\text {nd }}$ intercostal space on the right, over both subclavian and carotid arteries and over the abdominal aorta. The laboratory findings only showed a slightly elevated erythrocyte sedimentation rate (ESR) $(30 \mathrm{~mm} / \mathrm{h})$ and a moderately increased C-reactive protein level (CRP) (36 mg/l) with normal differential blood count. An initial ECG, chest radiograph and lung function tests were normal. The echocardiographical result of a mild aortic regurgitation could not explain the mentioned symptoms. Dopplersonography showed an osteal stenosis of the brachiocephalic trunk with a Ap max. of $32 \mathrm{mmHg}$. A magnetic resonance angiography (MRA) scan of the chest and neck showed an inflammation around the aortic arch, the supraaortal branches and the central pulmonary artery vessels. In addition, the aortic wall was thickened and concentric stenosis of the brachiocephalic trunk, the left common carotid artery and the proximal pulmonary arteries predominantly on the left side was found (fig. 1). Lung perfusion scan showing homogeneous decrease of radioisotope uptake of the entire left lung best explained the exertional dyspnea. The calculated relative uptake ratio of the right lung compared to the left was 3.65 .

The combination of clinical findings, laboratory results with slightly increased inflammatory parameters and the typical radiological changes diagnosed a Takayasu's arteritis with main involvement of the pulmonary arteries. Other differential diagnoses that were considered and therefore excluded were Wegener's granulomatosis, giant cell arteritis, Behçet disease, sarcoidosis, neoplastic disorders and systemic infectious diseases. Involvement of the renal artery that was suspected because of an abdominal systolic bruit could be ruled out in duplex sonography.

We started an immunosuppressive therapy with prednisone ( $1 \mathrm{mg}$ per kg once daily). Under this treatment the inflammatory parameters normalized within a month and the exertional dyspnea almost fully regressed within two months. Objective measurement of the patient's work capacity was not obtained before and after treatment. As a consequence of the systemic corticosteroids the patient 
felt nervous, gained $7 \mathrm{~kg}$ of weight and developed hypertension.

Decreased activity of the disease was verified with MR-angiography that showed a reduction of the perivascular gadolinium uptake. In addition, lung perfusion scan confirmed an increase of left lung perfusion with a right to left ratio of 2,03 (fig. 2B). After four months administration of corticosteroids, treatment was combined with methotrexate $15 \mathrm{mg}$ (i.m.) on a weekly basis. Consequently the prednisone dosage could be reduced to $5 \mathrm{mg} /$ day. Up to now no side effects relating to the methotrexate therapy have appeared. A control MRA under a combined immunosuppressive treatment confirmed a further decrease of the inflammatory process.

\section{Conclusion}

Dyspnea due to pulmonary artery involvement can be the initial symptom of Takayasu's arteritis. Simple clinical tests, including a complete pulse-status and blood pressure measuring at both arms can lead to the right diagnosis and should always be done beyond the auscultation of the heart and lungs in patients with dyspnea.

\section{Competing interests}

None declared

\section{Acknowledgement}

Written consent was obtained from the patient for publication of the patient's details.

\section{References}

I. Kerr GS, Hallahan CW, Giordano J, Leavitt RY, Fauci AS, Rottem M, Hoffman GS: Takayasu arteritis. Ann Intern Med 1994, I 20:919-929

2. Hall S, Barr W, Lie JT, Stanson AW, Kazmier FJ, Hunder GG: Takayasu arteritis. A study of 32 North American patients. Medicine 1985, 64:89-99

3. Kerr KM, Auger WR, Fedullo PF, Channick RH, Yi ES, Moser KM: Large vessel pulmonary arteritis mimicking chronic thromboembolic disease. Am J Respir Crit Care Med 1995, I 52:367-373

4. Hoffinan GS: Takayasu arteritis: lessons from the American National Institutes of Health experience. Int J Cardiol 1996, 54:99-102

5. Arend WP, Michel BA, Bloch DA, Hunder GG, Calabrese LH, Edworthy SM, Fauci AS, Leavitt RY, Lie JT, Lightfoot RW Jr, et al: The American College of Rheumatology 1990 criteria for the classification of Takayasu's arteritis. Artheritis Rheum 1990, 33: II29-II34

6. Sharma S, Kamalakar T, Rajani M, Krishan Talwar K, Shrivastava S: The incidence and patterns of pulmonary artery involvement in Takayasu's arteritis. Clin Radiol 1990, 42:177-I8I

7. Lupi E, Sanchez G, Horowitz S, Gutierrez E: Pulmonary artery involvement in Takayasu's arteritis. Chest 1975, 67:69-74

8. Vanoli M, Castellani M, Bacchiani G, Cali G, Mietner B, Origgi L, Scorza R: Non-invasive assessment of pulmonary artery involvement in Takayasu's arteritis. Clin Exp Rheumatol I 999, I 7:2 I 5-2 I 8

9. Yamada I, Shibuya H, Matsubara O, Umehara I, Makino T, Numano F, Suzuki S: Pulmonary artery disease in Takayasu's arteritis angiographic findings. Am J Roentgenol 1992, I 59:263-269

10. Elsasser S, Soler M, Bollinger C, Jäger K, Steiger U, Perruchoud AP: Takayasu disease with predominant pulmonary involvement. Respiration 2000, 67:213-215

II. Haque U, Hellmann D, Traill T, Venbrux A, Stone J: Takayasu's arteritis involving proximal pulmonary arteries and mimicking thromboembolic disease. J Rheumatol 1999, 26:450-453
12. Hara M, Sobue R, Ohba S, Kitase M, Sasaki S, Ogino H, Andoh K, Goodman PC: Diffuse pulmonary lesions in early phase Takayasu arteritis predominantly involving pulmonary artery. Comput Assist Tomogr 1998, 22:801-803

13. Devouassoux G, Pison C, Witmeyer P, Tony F, Coulomb M, Brambilla $\mathrm{C}$ : Pulmonary infarction revealing pulmonary Takayasu's arteritis. Respir Med 1998, 92:969-971

14. Kashiwabara K, Nakamura H, Sarashina G, Kishi K, Yagyu H, Kiguchi T, Kobayashi K, Kusama H, Matsuoka T: Chronic thromboembolic pulmonary hypertension associated with initial pulmonary involvement in Takayasu arteritis. Nihon Kokyuki Gakkai Zasshi 1998, 36:633-637

15. Brugiere O, Mal H, Sleiman C, Groussard O, Mellot F, Fournier M: Isolated pulmonary arteries involvement in a patient with Takayasu's arteritis. Eur Respir ] 1998, I I:767-770

16. Defaye P, Ferretti G, Benderbous R, Denis B: Localised primary lesion of the right pulmonary artery in Takayasu's disease. Arch Mal Coeur Vaiss 1996, 89:1217-1221

17. Lie JT: Isolated pulmonary Takayasu arteritis: Clinicopathologic characteristics. Mod Pathol 1996, 9:469-474

18. Ferretti G, Defaye P, Thony F, Ranchoup Y, Coulomb M: Initial isolated Takayasu's arteritis of the right pulmonary artery : MR appearance. Eur Radiol 1996, 6:429-432

19. Nakabayashi K, Kurata N, Nangi N, Miyake H, Nagasawa T: Pulmonary artery involvement as first manifestation in three cases of Takayasu arteritis. Int J Cardiol 1996, 54:177-183

20. Rocha MP, Guntupalli KK, Moise KJ, Lockett LD, Khawli F, Rockey R: Massive haemoptysis in Takayasu's arteritis during pregnancy. Chest 1994, 106:1619-1622

21. Maziarka D, Meleniewska A, Kurs J: Pulmonary changes as a result of pulmonary artery involvement during Takayasu disease: case report. Pneumonol Allergol Pol 1994, 62:299-303

22. Koyabu S, Isaka N, Yada T, Konishi T, Nakano T: Severe respiratory failure caused by recurrent pulmonary hemorrhage in Takayasu's arteritis. Chest 1993, I 04:1905-1906

23. Hlavacek $K$, Janik $V$, Tuma $S$ : Takayasu's arteritis with primary involvement of the pulmonary artery. Vnitr Lek 1993, 39:773777

24. Nunes H, Rarnos JM, Valerio L, Abreu J, Bernardes L, Salomao S: Pulmonary artery involvement in Takayasu arteritis. A case of right ventricular failure as presentation form. Rev Port Cardiol 1992, I I:775-780

25. Bletry O, Kieffer E, Herson S, Valere P, Masquet C, Lacombe P, Pilliere R, Carette MF, Chomette G, Godeau P: Severe pulmonary artery involvement of Takayasu arteritis. 3 cases and review of the literature. Arch Mal Coeur Vaiss 1991, 84:817-822

26. Horimoto M, Igarashi K, Aoi K, Okamoto K, Takenaka T: Unilateral diffuse pulmonary artery involvement in Takayasu's arteritis associated with coronary-pulmonary artery fistula and bronchial-pulmonary artery fistula: a case report. Angiology 1991, 42:73-80

27. Sandron D, Clarke JP, Guillevin L, Bouillard J, Pioche D: Takayasu's disease localized exclusively in the pulmonary artery. Rev Pneumol Clin 1989, 45:217-220

28. Hayashi K, Nagasaki M, Matsunaga N, Hombo Z, Imamura T: Initial pulmonary artery involvement in Takayasu arteritis. Radiology 1986, I 59:401-403

29. Hoffinan GS, Ahmed AE: Surrogate markers of disease activity in patients with Takayasu arteritis. A preliminary report from The International Network for the Study of the Systemic Vasculitides. Int / Cardiol 1998, 66:191-194

30. Choe $\mathrm{YH}$, Lee WR: Magnetic resonance imaging diagnosis of Takayasu arteritis. Int J Cardiol 1998, 66:175-179

31. Shelhamer JH, Volkman DJ, Parrillo JE, Lawley TJ, Johnston MR, Fauci AS: Takayasu's arteritis and its therapy. Ann Intern Med 1985, 103:121-126

32. Hoffinan GS, Leavitt TY, Kerr GS, Rottem M, Sneller MC, Fauci AS: Treatment of glucocorticoid-resistant or relapsing Takayasu arteritis with methotrexate. Arthritis Rheum 1994, 37:578-582

33. Ishikawa K: Survival and morbidity after diagnosis of occlusive thromboaortopathy (Takayasu's disease). Am J Cardiol I98I, 47:1026-1032

34. Sundt TM: Clinical-pathologic conference in thoracic surgery: proximal pulmonary artery obstruction secondary to Takayasu arteritis. J Thorac Cardiovasc Surg 200 I, I 2 I: 163-75 